\title{
EL PAPA FRANCISCO Y LA IGLESIA QUE SUEÑA
}

DOI: https://doi.org/10.52039/seminarios.v60i211.213

ALONSO MORATA MOYA*

\section{INTRODUCCIÓN}

Podemos decir que en la Evangelii Gaudium el papa Francisco traza las líneas por donde debe avanzar la Iglesia a lo largo de su pontificado. No olvidemos que esta exhortación apostólica quiere reflejar el trabajo del Sínodo sobre Nueva Evangelización y sus conclusiones. Por esta razón no es casualidad, sino que son unas palabras muy significativas de su propósito, las dos con las que comienza dicha exhortación. En cierto sentido marcan un subrayado repetido en su eco significativo: evangelium, buena noticia, anuncio feliz, positivo, constructor de personas alegres, etc. y gaudium, que expresa el regocijo interior que se refleja no sólo en el rostro, sino en la conducta entera de la persona.

El Papa nos invita en primer lugar a que nos quitemos la sensación de que el mensaje de Cristo es como una pesada losa que nos agobia y vivamos en la ligereza que la felicidad nos proporciona, en la visión del horizonte más claro que nos trae la Resurrección. No se puede anunciar el evangelio, la buena noticia por excelencia en estado de depresión. Nunca hemos tenido tantos medios como en nuestra sociedad, sin embargo, es verdad que parece que éstos han sido acaparados por gentes que tienen por dios el dinero y el poder, la influencia y la manipulación delos demás y, aparece un ámbito social lleno de personas tristes y desangeladas, insatisfechas.

No cabe duda de que el papa Francisco ha querido con esta exhortación decirnos cuál tiene que ser el talante del evangelizador en nuestro mundo actual. Más que con palabras y medios técnicos, la Palabra se transmite por hechos de la vida cotidiana. Nunca está de más recordar lo que ya en los primeros tiempos nos dice el autor de la Carta a Diogneto: «Los cristianos no se distinguen de los demás hombres, ni por el lugar en que viven, ni por el lenguaje, ni por su modo de vida. Ellos, en efecto, no tienen ciudades propias, ni utilizan un hablar insólito, ni llevan un género de vida distinto. Su sistema doctrinal no ha sido inventado gracias al talento y especulación de hombres estudiosos, ni profesan, con otros, una enseñanza basada en autoridad de hombres».

* Director de la Revista Seminarios y del Secretariado de la Comisión Episcopal de Seminarios y Universidades de la Conferencia Episcopal Española. 


\section{MARCADOS POR LA ALEGRÍA}

«La alegría del Evangelio llena el corazón y la vida entera de los que se encuentran con Jesús». Estas son las palabras con las que el papa Francisco comienza su Exhortación apostólica «Evangelii Gaudium» (La alegría del Evangelio). Tenemos aquí todo un programa de nueva evangelización, con fidelidad a la forma de vida a la que nos invita Jesús y camino abierto para curar la superficialidad y desesperanza que se apodera de nuestro mundo. Todos necesitamos y buscamos la alegría, pero no podemos contentarnos, ni nos satisface, la alegría facilona del chiste o la jarana. Anhelamos esa forma de gozo que llena el corazón del hombre y concita en su entorno un aire nuevo que hace respirable, incluso el ámbito de la dificultad. Ya podemos afirmar taxativamente que nadie puede comunicar el Evangelio si antes, no sólo está convencido, sino, sobre todo, muestra que el vivirlo ha cambiado su visión de las personas, que es capaz de comprender y perdonar, que no se busca a sí mismo, ni el triunfo social, sino el bien de los que le rodean, bien que se trasmite a todo el mundo en una actitud abierta, dialogante. No es fácil explicar con palabras estas dos que inician la exhortación del papa Francisco, sólo se entiende cuando se vive en profundidad de vida lo que supone ese mensaje no para el conocimiento de una doctrina, sino para el diseño de una forma de vida pisando en las huellas que Jesús mismo nos deja.

\section{LA TRANSMISIÓN DE LA FE}

El Papa recoge los trabajos del Sínodo dedicado a «la nueva evangelización para la transmisión de la fe» celebrado del 7 al 28 de octubre de 2012 en el Vaticano y los convierte en el programa de su pontificado. A lo largo de los 300 puntos que forman la exhortación, el pontífice habla de su visión de la Iglesia y del mundo, profundizando en ideas que ya ha anunciado durante este año largo. Francisco expresa su «sueño con una opción misionera capaz de transformarlo todo, para que las costumbres, los estilos, los horarios, el lenguaje y toda estructura eclesial se convierta en un cauce adecuado para la evangelización del mundo actual más que para la auto-preservación».

Recuperar el sentido de palabras que a lo largo de la historia de la Iglesia se han ido devaluando o enquistando en una significación que nada tenía que ver con su sentido pleno, como es la opción misionera. Ésta no puede quedar reducida al trabajo con los «infieles», a la marcha a otros países, porque la Iglesia o es misionera o es solo una organización plenamente estructurada en orden a un poder e influencia en el mundo. El único poder e influencia que ha de tener es servir de luz para que exista el amor, la capacidad de compartir bienes, la actitud hecha efectiva de ser generoso. Tantas y tantas aptitudes que definen los rasgos de las primeras constituciones-comunidades de la Iglesia en aquello que «co- 
menzó en Galilea» y se ha transformado en el mensaje de Dios a través de quien compartió nuestra vida, se hizo caminante a nuestro lado y sigue mostrándonos el camino, porque lo más importante es el avanzar en nuestro trayecto, para que el proyecto de fe-vida llegue a su plenitud en nosotros

Al comienzo de la Exhortación, el santo padre hace un llamamiento a todos los bautizados para que, con fervor y dinamismo nuevos, lleven a otros el amor de Jesús en un "estado permanente de misión». Y para realizar esta tarea, Francisco invita a «recuperar la frescura original del Evangelio», encontrando «nuevos caminos» y «métodos creativos». De igual modo habla de «una conversión del papado» para que sea «más fiel al sentido que Jesucristo quiso darle» y «a las necesidades actuales de la evangelización». Sobre las Conferencias Episcopales señala su deseo de que puedan dar una contribución para que «el efecto colegial» tenga una aplicación «concreta» que aún «no se realizó plenamente».

La misión, como indicábamos más arriba, no es, en la consideración del sumo pontitice no es una actuación de un momento, sino un «estado permanente» esencial para definir, y distingue a la Iglesia de cualquier otro grupo que tiene su base en ideologías, modos sociales o filosofías. El estado de misión lo es de apertura a todos, no para hacer adeptos, ni ganarse socios que nos mantengan con sus cuotas, sino para anunciar la «vida» gratis, como gratis lo hemos recibido del amor del Padre que no duda en enviar a su Hijo para que nos enseñe el "camino» caminando a nuestro lado. Si lo sentimos así y lo transmitimos a los hermanos sin duda que se recuperará la «frescura del evangelio» y encontraremos, «nuevos caminos y métodos de evangelización».

\section{NECESIDAD DE CONVERSIÓN}

Lo primero que hace el papa es pedir una conversión del papado, para que sea fiel al encargo que le ha dado Cristo y responda a las expectativas que tanto creyentes como no creyentes tienen siempre con respecto a su forma de vivir y dar testimonio a todos de que sigue la trayectoria que le marca el camino evangélico. Llama también la atención sobre la «colegialidad de los obispos» que, reconoce, aún no se ha realizado plenamente. Y el tema de la colegialidad es importante, ya que pertenecemos a un pueblo que debe caminar unido por encima de razas e ideologías. No se trata de una estructura cerrada y perfectamente engranada por los que la constituyen, sino una fuerza de vida que tiene que estar abierta a la orientación del Espíritu Santo para ser palabra creíble en cada tiempo y comprendida por todos. El sentido de diálogo, nada dogmático, con una escucha que permita ponerse en el lugar del interlocutor y ver las cosas desde su ángulo de vista, pudiendo así construir juntos la Iglesia que el Padre quiere. «Porque Dios no ha enviado a su Hijo al mundo para condenar al mundo, sino para que el mundo se salve por él». Una Iglesia que es una invitación a la 
confianza constante, a eliminar toda visión del Padre como un juez implacable, demasiado adusta, como para no caer en exageraciones. El Papa, siguiendo el camino de Jesús, nos la quiere presentar como la luz que invita a acercarnos para beneficiarnos de su riqueza.

a) Nuevos evangelizadores. El llamamiento del santo padre no es sólo a los sacerdotes. No debe hacerse de la forma rechazada más arriba: por obligación y en situación de «no hay más remedio que hacerlo». La nueva evangelización no se podrá llevar a cabo sin un nuevo evangelizador, que haga sonar la música, siempre nueva, del anuncio, como decíamos más arriba. Recuperar la frescura del evangelio es sentir íntimamente el sonido primigenio que tuvo en tiempos de Jesús y hacerlo atractivo para que la gente lo escuche como esa palabra salvadora para la humanidad. Es cierto que los métodos no son nunca un fin en sí mismos, pero, si son acertados y sintonizan con las antenas receptivas de los jóvenes (y mayores) de cada generación, ayudan a la difusión del evangelio. Hace unos días, en un grupo de catequesis, hablándoles de la vocación, como una llamada que Dios hace a todo hombre o mujer para que sea feliz en su misión en el mundo (en el matrimonio, en una soltería dedicada a investigación o a cualquier fin, o en la vida consagrada y el ministerio sacerdotal, uno de ellos me preguntó ¿y si uno quiere ser master chef, también es vocación? Como es natural, le dije que sí, pero me di cuenta de que esa pregunta no nos la hacíamos hace unos años. El efecto de la televisión en las orientaciones de los jóvenes es, al menos, atendible.

En lo referente a la llamada al ministerio ordenado es claro que con medios de hace unos años, no muchos, no se suscita la pregunta, que es más importante que dar las respuestas cocinadas, ¿por qué? El lenguaje, el significado contenido en muchas palabras no es el mismo que le dábamos hace unos años. Cada generación de jóvenes hemos tenido nuestra «jerga», pero en los últimos 30 años se ha convertido en una especie de «sub-lenguaje» o un lenguaje propio que distingue y separa. Los jóvenes se sienten dichosos de hablar de forma que no los entiendan los mayores. Nuestra época de juventud se inventaba ese lenguaje con una sílaba que 'desconcertaba' en medio de palabras normales, propia de un grupo de amigos. Así sólo ellos entendían lo que querían comunicarse. Pues en este momento hay trucos conductuales que son un lenguaje para marcar fronteras en ciertas edades y sólo descubriendo, con mucho tino, lo que significan los signos podremos entrar en la realidad de las inquietudes, de los proyectos, de la interioridad del o de la joven.

b) Ver a los jóvenes con los ojos amorosos del Padre. Es fácil juzgar y hacerlo negativamente. Cuando leemos cualquier estudio sociológico sobre los jóvenes, siempre sacamos conclusiones negativas y la verdad no está en los resultados de un estudio. Éstos a lo más nos hablan de las carencias y no de las virtudes, nos dicen lo que no hay. Por esta razón hablaba antes de suscitar preguntas que remuevan el corazón de los jóvenes hasta llegar a la nuclear de su vida ¿dónde 
está mi puesto en el mundo? Que se parece a la que el joven del evangelio ¿qué tengo que hacer para salvarme? Porque no 'se salva', o sea, no alcanza el camino de su felicidad plena, aquel que anda dando tumbos en la vida saltando de 'flor en flor', sino el que elabora un proyecto como respuesta a sus inquietudes y a una llamada que todos recibimos. Eso supone también tiempo de reflexión, de silencio y escucha para saber formular la pregunta que marca la orientación de nuestra vida. Es un aprendizaje que debe hacer todo evangelizador si no quiere «predicar en desierto». La respuesta a la llamada del Señor es exigente, aunque lleve más ganancias que pérdidas, ocurre que muchos de los jóvenes y menos jóvenes tienen miedo a dejar los bienes que se ven (riquezas de tipo personal: simpatía, atractivo, liderazgo... y también las riquezas materiales: tener para vivir de sobra). En el texto de joven rico (Mt 19, 16-22; Mc 10, 17-22; Lc 18, 18-23) cuando le propone «si quieres ser perfecto, vete, vende lo que tienes y dáselo a los pobres... y luego ven y sígueme... se marchó apenado porque tenía muchos bienes». No había descubierto que eran para darlos a los demás. Cree elegir la riqueza y queda sumido en la pobreza de egoísmo.

c) Bajo el signo de la apertura. El santo padre pide signos de la acogida de Dios: "tener templos con las puertas abiertas en todas partes» para que quienes buscan no se encuentren "con la frialdad de unas puertas cerradas». Hay un ejemplo que a mí me habla de cambio de época, de sociedad cambiante continuamente: cuando era niño, las puertas de las iglesias del pueblo estaban siempre abiertas, no había peligro, salvo algún hurtillo en el cepillo de personas que no tenían para comer, ni de profanaciones, ni de robos sonados... la misma sociedad de cristiandad era guardiana de los lugares de culto y éstos siempre estaban abiertos para recibir. Otra cosa era la puerta de los sacramentos y esas, dice el papa que «tampoco las puertas de los sacramentos deberían cerrarse por una razón cualquiera».

d) Conscientes de la situación de nuestro mundo. ¿Cómo es nuestra visión de la economía del mundo? En nuestra Europa hemos creído que con pergeñar una Comunidad Económica Europea teníamos resueltos los problemas de distribución de riqueza, de trabajo para todos, de unidad en los criterios básicos de una democracia participativa, pero nos hemos olvidado de una escala de valores que sustente esa actitud de unidad en los objetivos y fines. Si el objetivo es una mayor distribución y un sentido de justicia, queda vacío si no existe una generosidad que va más allá de nuestras posturas naturales y que se llama 'caridad', que no es simplemente dar algo a quien no tiene, sino un talante continuo de conducta, una forma de hacer y ser. ¿Por qué habla el papa de que el sistema económico actual es «injusto en su raíz»? «Esa economía mata» porque predomina «la ley del más fuerte», dice. La cultura actual del «descarte» hace que «los excluidos no son 'explotados' sino desechos, 'sobrantes'». Del mismo modo denuncia los «ataques a la libertad religiosa» y las nuevas situaciones de persecución a los cristianos. 
También habla de la importancia de la familia, que «atraviesa una crisis cultural profunda». E insiste en «el aporte indispensable del matrimonio a la sociedad».

Sobre estos hechos es urgente que la actuación de los cristianos sea clara respuesta mediante una conversión, un volver el rostro hacia los otros. Sin duda ninguna nos hemos contaminado de esa economía injusta que mata, que excluye. Acostumbrados a vivir en una sociedad en la que lo cristiano, aunque fuese en formas y distribución del calendario, era como el substrato en el que se asentaba la marcha de la sociedad. Vivíamos, además, en una sociedad monocultural (con diferencias pequeñas). Ahora nos sentimos invadidos por gentes que buscan una mejor calidad de vida, se mezclan costumbres o se encierra cada cual en las suyas. Las creencias, cuando permanecen, son un mero barniz en la persona que se manifiesta de lleno en la fiestas de tal o cual patrón o patrona, ¿cómo hacer que todas esas personas, que se emocionan ante una imagen de la Virgen o del Crucificado, descubran que la vida cristiana está hecha de una continuidad en la vida de actos que traduzcan esa 'supuesta' creencia que les lleva a emoción, sólo a una reacción afectiva?

La crisis cultural es muy honda; en esta sociedad del fragmento, cada tesela parece formar una figura sin sentido, pero el puzle de la vida coherente no se comienza ni siquiera a vislumbrar. Este ambiente hace que tampoco el compromiso de vida de dos personas sea considerado por la mayoría de las parejas 'compromiso de por vida' que ha de madurar, sino un vivir juntos mientras quieran. Eso de comprometerse en matrimonio parece fuera de sitio.

\section{4. ¿QUÉ DEBEN HACER LOS AGENTES PASTORALES?}

El papa enumera las «tentaciones de los agentes pastorales»: individualismo, crisis de identidad, caída del fervor. Exhorta a «ser signos de esperanza» poniendo en marcha la «revolución de la ternura» y a vencer la «mundanidad espiritual». El Papa dedica unas líneas para hablar de los que «se sienten superiores a otros» por ser «inquebrantablemente fieles a cierto estilo católico propio del pasado» y, «en lugar de evangelizar», lo que hacen es «clasificar a los demás». Y también recuerda a quienes tienen un «cuidado ostentoso de la liturgia, de la doctrina y del prestigio de la Iglesia, pero sin preocuparles que el Evangelio tenga una real inserción» en las necesidades de la gente.

De todas las tentaciones y exhortaciones indicadas haría hincapié en dos importantes: el individualismo y la revolución de la ternura, porque, en cierto modo incluyen los demás:

a) El individualismo: nos lleva a centrar todo en nuestros gustos, con lo cual la identidad sacerdotal-ministerial que debe responder a la actualización de la misión de 'los apóstoles' en este momento de la historia, se convierte en una 'acción caprichosa que puede reducirse a tener unas ceremonias ostentosas, a defender la tradición de forma sesgada e interesada y, en cierto modo, a una 
espiritualidad cuyo fin sea el 'brillo propio en el mundo' y no la 'evangelización' de nuestros coetáneos. Esta salida al encuentro de los otros (a las periferias) supone una salida anterior de mí mismo y de mis caprichos para ponerme total e incondicionalmente a la escucha de lo que Dios quiere de mí como servidor fiel de su Palabra. Como el apóstol Pablo que no sea yo, sino Cristo quien vive, predica, actúa a través de mi persona que es ya totalmente suya. Lo cual no es ninguna forma de esclavitud, sino la plenitud del ser libre.

b) La revolución de la ternura. Nuestro mundo necesita cada vez más de testigos de la misericordia, de personas capaces de escuchar el grito de socorro que, a veces sin ser conscientes, lanzan muchos hombres y mujeres de nuestro tiempo. Hay episodios, ya en el antiguo testamento, que están llenos de la ternura de Dios: "Cuando Israel era un niño, yo le amé, y de Egipto llamé a mi hijo. Cuanto más los llamaba, más se alejaban de mí: (...) Y con todo yo enseñé a Efraín a caminar, tomándole en mis brazos, mas no supieron que yo cuidaba de ellos. Con cuerdas humanas los atraía, con lazos de amor» (Os 11, 1.4a) «la llevaré al desierto y allí le hablaré al corazón» (Os 2,16). Dios nos ha cuidado y nos cuida de siempre y en todo momento, es preciso que nos demos cuenta de ello y pongamos el oído atento para escuchar las palabras que él dirige a nuestro corazón. No podemos actuar como jueces implacables. Ni hacer-dice el papa Francisco-del confesonario un lugar de tortura. Es siempre lugar de misericordia, de dar ánimos para seguir el camino al que el Señor nos invita. Esta ternura nos conducirá a sintonizar con las necesidades de nuestros contemporáneos

\section{El PUEBLO DE DIOS. LA MISIÓN DEL LAICO Y LA MUJER EN LA IGLESIA}

¿Cómo debe ser el pueblo de Dios? Un pueblo que camina desde el vínculo de la caridad, del amor, en el que cada cual cumple el rol asignado con total desprendimiento sin que la comunidad corra el peligro de caer en envidias o en celos «dentro del Pueblo de Dios y en las distintas comunidades». No vale eso de rivalidades por prestigio, ni siquiera por proclamar que tienen más fieles que otra comunidad cercana, porque una sola es la comunidad, la Iglesia, y las comunidades locales o diocesanas se integran en ella, cada una con sus características, sus dificultades y potencialidades, llevando a cabo la misión total en el territorio que deba desarrollarse su tarea pastoral. Y es muy importante que se deje de identificar de una vez Iglesia con ministerio presbiteral. Todo el pueblo de Dios es un pueblo sacerdotal y los laicos han de desempeñar su misión con responsabilidad. No es que sea totalmente nuevo en cuanto a doctrina, pero desde el Vaticano II hemos ralentizado demasiado ese hacer crecer la responsabilidad de los laicos, los hemos mantenido muy «al margen de las decisiones» que tiene como raíz "un excesivo clericalismo». Ésta es una de las tareas pendientes de nuestra Iglesia: no debemos hacer casta clerical, somos una parte del pueblo de Dios, importante sí, por su misión aglutinadora y de servicio a la comunidad a 
tiempo pleno, pero nunca quienes tienen la última palabra, cuando una comunidad en armonía plantea la dinámica de acción en ese territorio. La voz del laico y su acción son muy importantes.

Otro aspecto importante de la nueva Iglesia es el rol de la mujer, afirma el papa que «todavía es necesario ampliar los espacios para una presencia femenina más incisiva en la Iglesia». Muchas de ellas han entregado parte de su vida al servicio de la comunidad a la que pertenecen y lo han hecho con eficacia y generosidad. Es, además, muy necesaria la visión femenina dentro de las comunidades eclesiales, porque ellas tienen la capacidad de diferenciar y descubrir allí donde se actúa con amor y cómo llevar a cabo esta tarea de integración de los alejados y de los que rechazan, por cualquier causa el evangelio.

\section{LA ATENCIÓN A LOS JÓVENES. LA VIDA COMO VOCACIÓN}

Otra de las tareas de su programa es la atención a los jóvenes. Necesitan un acompañamiento, tenemos que acertar en la manera, no de retenerlos, sino de que se sientan felices en la Iglesia cumpliendo su papel, aportando la alegría y la intrepidez de la juventud, su visión nueva de las cosas. Ayudándoles a liberarse de las esclavitudes que, bajo la capa de progresismo, les quiere imponer el mundo actual; pero no sustituyéndolas por otras esclavitudes, sino por la libertad de los hijos de Dios, que aman, no por imposición, sino por sentimiento profundo de identidad con Jesús. Recuerda además a los jóvenes que deben tener «un protagonismo mayor» Una de las tareas que nos señala el Papa es la de promover vocaciones en toda la Iglesia, consciente de la escasez de las mismas en algunos lugares, advirtiendo siempre de que «no se pueden llenar los seminarios con cualquier tipo de motivaciones». Es necesario un discernimiento claro mediante un acompañamiento que no queme etapas, sino ayude a madurar la decisión y a comprobar el substrato personal de los candidatos al ministerio ordenado. Son importantes las bases humana, espiritual, dialogal y pastoral para poder construir sobre ellas la persona del nuevo y renovado pastor, el que el mundo de hoy necesita como transmisor de la palabra en el lenguaje actual que precisa para ser entendida.

\section{UN SOLO PUEBLO, ENCARNADO EN MÚLTIPLES CULTURAS}

$Y$ esto recordando que «el cristianismo no tiene un único modo cultural» y que el rostro de la Iglesia es «pluriforme». No debemos adaptar las culturas a nuestra predicación, sino hacerse «griego con los griegos, romano con los romanos, siendo todo en todos». Del mismo modo reafirma la «fuerza activamente evangelizadora» de la piedad popular e invita a los teólogos a llevar en el corazón «la finalidad evangelizadora de la Iglesia» y a no contentarse con «una teología de escritorio». Son importantes estas palabras. Porque, si es necesaria 
una preparación profunda, de nada vale si se quedan en palabras que no llevan a Dios, sino son una pirueta en el aire para que la gente admire la sabiduría (o el saber) teórico de unos señores que, como decían nuestros mayores, estaban muchos años estudiando para aprender a decir misa y luego la leían. Dar sensación de que se habla de lo que se vive, no de lo que se sabe, preparar bien la vida y las palabras, dejando actuar después al espíritu, que nos dirá lo que hemos de comunicar en cada momento.

a) Nuestras homilías. A propósito de esto habla sobre la forma de predicar, y señala el papa Francisco que la homilía «debe ser breve y evitar parecerse a una charla o una clase», debe saber decir «palabras que hacen arder los corazones», huyendo de «una predicación puramente moralista o adoctrinadora». De esto nos da ejemplo constantemente en sus homilías cotidianas en Santa Marta y en las que dirige a los fieles congregados en la plaza de San Pedro o en cualquier otro lugar donde tenga que predicar. Van directamente al corazón, sin dibujos innecesarios, con la claridad y la exigencia que pide el evangelio; que estén llenas de vida, una vida que rebosa desde el interior. La mejor llamada es la que se hace desde un corazón lleno que comunica aquello de lo que está rebosante. No la palabra vacía, por muy bella que sea la estructura literaria. Hemos de reconocer que el moralismo ha desfigurado en muchas ocasiones el verdadero rostro del Evangelio y lo ha llevado a la consideración de un cúmulo de «prohibiciones» que lo han hecho rechazable para quienes se creen libres, aunque estén bajo esclavitudes que, un horizonte gozoso del Evangelio, les ayudaría a superar. Las normas de ética cristiana dimanan de una forma fiel de vivir la Palabra, no al revés. Durante siglos hemos dado la impresión de ser moralistas más que teólogos, de poner la norma por encima de la Palabra liberadora de Cristo, su Buena Noticia para todos.

b) Papel de la religión cristiana en la sociedad. Un rasgo importante que señala el santo padre es el papel social que desempeña la religión cristiana. Es sabedor de los diversos intentos de reducirla a una creencia en lo más íntimo del corazón o para ocasiones y lugares muy concretos, por eso indica que «nadie puede exigirnos que releguemos la religión a la intimidad secreta de las personas, sin influencia alguna en la vida social». De hecho, el secularismo militante (que no quiere poner, al menos en pie de igualdad, la transcendencia) está vaciando de valores la conducta de los más jóvenes, contagiados por la superficialidad de sus mayores, por el «todo vale» con tal de que sea de mi gusto. La religión cristiana ha de ser luz para una paz social constructiva y llena de fuerza, que contemple que el hombre es cuerpo, alma y espíritu: lo material, lo animado y lo transcendente. Mucha importancia da también, junto a las vocaciones y al diálogo, la otra pata de su programa, a la lucha por la justicia, recuerda que «la opción por los pobres es una categoría teológica» antes que sociológica. Por eso indica, «quiero una Iglesia pobre y para los pobres. Ellos tienen mucho que enseñarnos». Esta consideración de los pobres como categoría teológica, está 
presente en toda la predicación de Jesús: «Te doy gracias, Padre, Señor de cielo y tierra, porque has ocultado estas cosas a los sabios y se las has revelado a la gente sencilla». «Bienaventurados los pobres, porque de ellos es el Reino de los cielos», además de su conducta cercana a los más necesitados, su interés por el enfermo, por quien está vacío, por el que tiene dinero, pero no es nadie (como Zaqueo), su muerte despojado de todo, incluso de la dignidad humana, Él que es Dios... todo en la vida y la Palabra de Jesús nos invita a no volver el rostro al ver al pobre, sino acercarnos para aprender de ellos. Curioso resulta, al menos, que en tiempos de mayor necesidad en nuestra sociedad, la acción solidaria era más fácil de encontrar. El Papa ha huido desde el principio de su pontificado de toda ostentación, de toda señal de poderío que no sea el amor, la sencillez, la cercanía, el gesto con los necesitados, con los que tienen un aspecto poco agradable a causa de deformaciones o enfermedades. Salir a las periferias, no quedarnos instalados en nuestra comodidad.

A ellos hay que añadir también a los más débiles, a quienes, recuerda el papa, debemos cuidar, «los sin techo, los tóxico-dependientes, los refugiados, los pueblos indígenas, los ancianos cada vez más solos y abandonados», los migrantes, las víctimas de la trata de personas, mujeres que sufren situaciones de exclusión. $Y$ deteniéndose en especial en los niños por nacer, recuerda que «no debe esperarse que la Iglesia cambie su postura sobre este tema» y que «no es progresista pretender resolver los problemas eliminando una vida humana».

Francisco también habla de la paz y explica la necesidad de «una voz profética» cuando se quiere construir una reconciliación falsa que «silencie» a los más pobres mientras «algunos no quieren renunciar a sus privilegios». Indica cuatro principios para la construcción de una sociedad «en paz, justicia y fraternidad»: trabajar a largo plazo, sin obsesionarse por resultados inmediatos; obrar para que los opuestos alcancen una unidad pluriforme que engendra nueva vida; evitar que la política y la fe se reduzcan a la retórica; aunar globalización y localización.

\section{LA UNIDAD DE LOS CRISTIANOS Y EL DIÁLOGO CON OTRAS RELIGIONES}

Trabajar por la unidad. La evangelización también implica un camino de diálogo que abre a la Iglesia para colaborar con todas las realidades políticas, sociales, religiosas y culturales, recuerda el pontífice. Señala el ecumenismo como «un camino ineludible de la evangelización». El caminar hacia la unión, a la realización de «que todos sean uno» es una de las realidades que tenemos que afrontar y nos duele y la importancia del enriquecimiento recíproco. Mucho se ha avanzado en este camino hacia el entendimiento y diálogo, capacidad de encuentro y valoración de la vida, liturgia, peculiaridades de los hermanos. Este diálogo interreligioso «es una condición necesaria para la paz en el mundo». Y frente a episodios de violencia invita a «evitar odiosas generalizaciones, porque el verda- 
dero islam y una adecuada interpretación del Corán se oponen a toda violencia». Por otro lado subraya que «el debido respeto a las minorías de agnósticos o no creyentes, no debe imponerse de un modo arbitrario que silencie las convicciones de las mayorías creyentes, o ignore la riqueza de las tradiciones religiosas». Quizás el camino de convergencia nos venga por ese dirigirnos a un Dios que es Padre para todos y que nos invita a mostrar al mundo el rostro de la paz. Nunca más guerras de religión. Tampoco caminos hacia eclecticismos, sino hacia el encuentro, porque una realidad gnóstica retrasaría la comprensión entre nosotros y desvirtuaría lo que es el camino ecuménico.

\section{CONCLUSIÓN}

Los encargados de llevar el mensaje. Son verdaderamente importantes los mediadores. El santo padre habla de los «evangelizadores con Espíritu». Ellos son quienes se «abren sin temor a la acción del Espíritu Santo» que «infunde la fuerza para anunciar la novedad del Evangelio con audacia (parresía), en voz alta y en todo tiempo y lugar, incluso contracorriente». Son evangelizadores que oran y trabajan, conscientes de que la misión es una pasión por Jesús y por su pueblo. Y recuerda a los fieles: «Si logro ayudar a una sola persona a vivir mejor, eso ya justifica la entrega de mi vida». Finaliza con una oración especial a María «Madre del Evangelio», «porque cada vez que miramos a María volvemos a creer en lo revolucionario de la ternura y del cariño». Se necesitan, en conclusión, unos evangelizadores abiertos a la escucha al espíritu, con firmeza en sus convicciones, que lleven la vida nueva y contagien la misma a aquellos que los vean. Sin dogmatismos innecesarios, pero acogiendo la visión de los otros, para que la posibilidad de encuentro sea real. Orar, como el Papa Francisco ha hecho estos días, invitando a la unión de todos los creyentes, a quitar estorbos que impiden una relación fluida y fraterna. Necesitamos encuentros desde el corazón, para que el Señor obre por nuestro medio el milagro de «que todos sean uno, como el padre y yo somos uno». La Nueva Evangelización sea una nueva primavera del Espíritu que guía nuestras vidas por CAMINOS DE ALEGRÍA. 